\title{
Interactive comment on "A Limited Effect of Sub-Tropical Typhoons on Phytoplankton Dynamics” by Fei Chai et al.
}

\author{
Waldemar Walczowski (Referee) \\ walczows@iopan.gda.pl
}

Received and published: 12 October 2020

General comments

The study raises the problem of the influence of tropical and sub-tropical cyclones on the primary production of the ocean. This type of work was mainly based on satellite data. The innovative aspect of the manuscript is the use of data from the biogeochemical Argo float (BGC Argo), in addition to satellite data. This method allowed the authors to draw new conclusions, most of them contrary to the previous works. Data from the upper $1000 \mathrm{~m}$ water column collected by the BGC Argo with a frequency of one day (measurements were made every night) allow observations of temporal evolution (and spatial changes) occurring near the sub-tropical typhoon Trami passage. Thanks to 
these data, the authors can conclude that the observed enhancement of chlorophyll concentration in the surface layer is not the result of increased primary production (as previously thought only on the basis of satellite observations), but due to the displacement from deep layer of chlorophyll maxima to the surface. It is a well-written research paper with clearly defined assumptions and interesting, original, novel results. Construction of the manuscript is logical, paper is concise. The main weakness of the manuscript is the lack of reference to the Argo float position and trajectory. Autos say that 'Typhoon Trami passed over the BGC-Argo float'. Figure 1 clearly shows that the centre of the typhoon was approximately 60-100 nautical miles from the float position. Also the wind speed (Fig. 3a) shows that the float was not in the centre of the typhoon. This may not be relevant to the performed analysis, but should be explained in more detail than is done on line 209. The potential impact on the results of the spatial variability of the ocean properties should also be explained. The Argo float does not stay in place, it drifts. Significant changes in SST and chlorophyll content are also visible before the typhoon passes near the float (Fig. 2). Another weak point of the article are the repetitions, which the authors unfortunately did not avoid. Despite these weaknesses I consider that the manuscript is a valuable contribution to understanding the influence of cyclones (typhoons) on the ocean in general, and on primary production in particular. At the same time, the article shows the importance and usefulness of the Argo program. The use of BGC floats profiling with frequency higher than the commonly used 10 days gives additional possibilities to conduct research on short-term phenomena.

\section{Specific comments}

Lines 117-119 repeated information from lines 88-89 Lines 121-122 (float) 'was sampling daily from $1000 \mathrm{~m}$ depth to the surface at $10 \mathrm{~m}$ intervals' Comment: what is the float measurements vertical resolution? In lines 90-91 you write 'Measurements were made every night (around 22:00 local time) to avoid in-vivo fluorescence nonphotochemical quenching, with $\sim 1 \mathrm{~m}$ vertical resolution'.

Printer-friendly version

Discussion paper 
Line 124: 'The BGC-Argo float profiles' Comment: There are 'sections' or 'section charts' at Fig $2 a$ and $2 b$, not 'profiles' (see comment to Fig. 2 in technical corrections).

Line 133: 'at 0.18 and $0.15 \mathrm{mg} \mathrm{chl} \mathrm{a/m3}$, respectively. These increases represent changes of 0.13 and $0.08 \mathrm{mg} \mathrm{chl} \mathrm{a/m3}$, respectively, above the concentration measured on September 29 before the typhoon approached to the area.' Comment: Some miscalculation. $0.18-0.15=0.03 ; 013-0.08=0.05$. What was the concentration in September 29 ?

Line 148: 'The calculated profiles of temperature' Comment: same as in line 124.

Line 208, Figure 1. I am not sure if the method of representing the effects of a typhoon transition (Figure 1) is optimal. The averages for the 20-day period (September 10September 30 and October 1- October 20) should strongly underestimate the effects of typhoon activity. Therefore, such significant temperature anomalies for September 28 and 29 are surprising. At the same time, no visible effects for dates before September 23.

Lines 208-210. What is the distance of the float to the typhoon centre?

Lines 239-240: 'The results clearly show mixing is overwhelming the dynamics comparing with the upwelling' Comment: This is too general statement that should not be drawn from a single observation.

\section{Technical corrections}

I am not a native English speaker and I will not correct linguistic errors, yet in my opinion the article requires linguistic intervention. For example: lines 49-50 'Thus, strong typhoons, e.g., category 4 or 5 , in mid-latitude regions are generally characterized as fast 50 moving and strong typhoons : This sentence needs improvement (strong typhoons are strong typhoons). Figure 1. The float route should be showed (if the map scale allows). Figure 2. Title 'Profiles of temperature (a) and chlorophyll' is not correct. Figures $2 \mathrm{a}$ and $2 \mathrm{~b}$ show not profiles but sections or section charts, while figures $2 \mathrm{c}$ and

Printer-friendly version

Discussion paper 
$2 d$ show time series. The same remark applies to Figs $4 a$ and $4 b$.

Interactive comment on Biogeosciences Discuss., https://doi.org/10.5194/bg-2020-310, 2020. 